\title{
Experimental analysis of mechanical behaviour of a sandwich beam with combined core.
}

\author{
A.Arbaoui \\ Laboratoire des matériaux minéraux \& composites \\ Université M'hamed Bougara Boumerdes Algérie
}

\section{I) Introduction}

The Sandwich structures are of great interest in a variety of complex structures used in aeronautics, ship building and civil engineering.

The design of these structures, in which thin facings are separated by a thick layer made of a light material, dates back to the $19^{\text {th }}$ century [1], and these structures have rapidly expanded, starting from the middle of last century, with the development of aeronautics.

In civil construction, this structure replaces bricklaying (vertical cladding) and roof tiling (horizontal cladding). In building it is used not only for mechanical strength but also for thermal and acoustic insulation (doors, insulating walls, cold room, and cladding).

In Algeria, the sandwich panel has been manufactured on an industrial scale since 1980 (in the aftermath of the Al-Asnam earthquake) using a design which involves steel sheets and a light and thick polyurethane. Other designs have been made since 2003 in order to meet the high demand for house building which followed the devastating earthquake of Boumerdès.

The sandwich panels consist of thin facing, also called skins or sheets, sandwiching a core. Whereas in laminated structures the layers have a more or less similar behaviour, in sandwich structures the core and the skins play rather different roles. The facing are made of high strength material and also support axial forces. The core must keep the skins apart and stabilise them, and therefore it must have some rigidity against perpendicular deformations and transversal shearing. The materials used are often likened to visco-elastic isotropic or orthotropic materials. [2]

When choosing the components of a sandwich panel one seeks to minimise its mass, optimise it resistance and meet its planned lifetime. When modelling these structures, one assumes the elasticity principles embodied in Hooke's law. A number of approaches, with alternative simplifications to deal with the heterogeneities of the components, have been proposed to solve the problems associated with these structures.

In this study we introduce a change in the conception of the core of the sandwich panel through inserting a thick layer of polystyrene between two layers of polyurethane. As the initial sandwich structures, the two layers of polyurethane, are placed between the metallic sheets. The new conception allows a collage of all elements together without using an external agent (glue). The two materials are similar by their physical characteristics but the polystyrene has a much lower cost. 
Since polyurethane and polystyrene have comparable mechanical properties, one can attempt a homogenisation along the thickness because the width of polyurethane is much reduced. This simplification enables us to determine the value of the shearing modulus of the combined core.

\section{I) Design and dimensions of the sandwich structure}

The thickness of the sandwich panel with a polyurethane core varies from 4 to $6 \mathrm{~cm}$. In the new design, the thickness of the combined core remains unchanged for materials with close densities (fig.1 and fig.2).

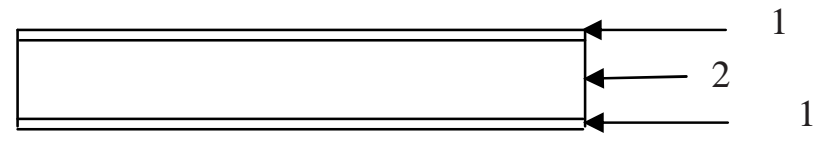

Fig.1. Sandwich panel with a homogeneous core 1. Metal skins 2. Polyurethane

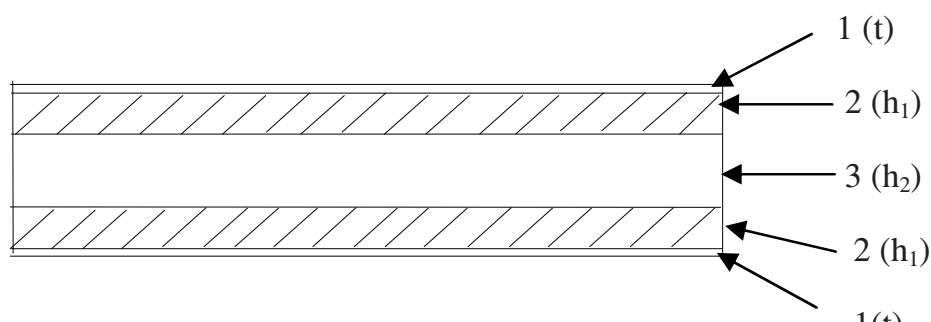

Fig. 2. Sandwich panel with a combined core

1. Metal skins 2. Polyurethane 3. Polystyrene

Placing the polyurethane layer near the skins serves to harden the latter so that they have a better stiffness under normal strains when the transversal section of the structure bends. The distributions of normal strains of the structure have been described in the literature $[3,4,5]$. The skins are thin $(1$ $\mathrm{mm}$ ), their stiffness under flexure is negligible, and hence they behave like membranes. Since the elasticity moduli of the core materials are infinitely smaller than the elasticity moduli of the skins, we neglect the normal strains in the layers of the core, so that they only support the shear. Nevertheless the stiffness of the core materials must be enough to prevent their deformation, so we must consider materials which are incompressible in the vertical plane when applying loads. The thickness of the panel remains constant and does not depend on the loading rate.

\section{II) Experimental determination of the shear modulus of polyurethane and polystyrene}

Through this test, we shall attempt to develop a pure and uniform shearing state within the section where the deformation measurements are made. This test can be realised in a large variety of ways because of the different possibilities available for introducing the load. However the criteria for choosing the set-up remain the uniformity and purity of the strain field, the difficulty in preparing the 
test piece, the dispersion and validity of the measurements, the failure, the simplicity of the test, and the cost [5].

\section{III) Torsion of axisymmetrical test-tubes}

The torsion test is the reference test whenever one needs to introduce a plane shearing within a given material. This test can be carried out with a full cylinder or with a tube with thin walls. For fibre composite materials, it is difficult to set up this test-tube and its cost can be high, but this is not the case for polymer materials such as polyurethane and polystyrene. This test will enable us to determine the instantaneous and long term shearing modulus. For longer applications of the constant load (400 hours), we will determine the mechanical properties needed to calculate the creep of the beam since the materials making up the latter have viscoelastic properties.[2]

\section{IV) Preparing the test-tubes and tests}

In order to establish the shearing modulus of the filling material, we take a sample in the form of an empty cylinder with an outer diameter of $50 \mathrm{~mm}$ and an inner diameter of $41.8 \mathrm{~mm}$. The length of the test tube depends on the thickness of the material; we take a value of $36 \mathrm{~mm}$. This dimensions were adopted for the two materials we studied (fig. 3).

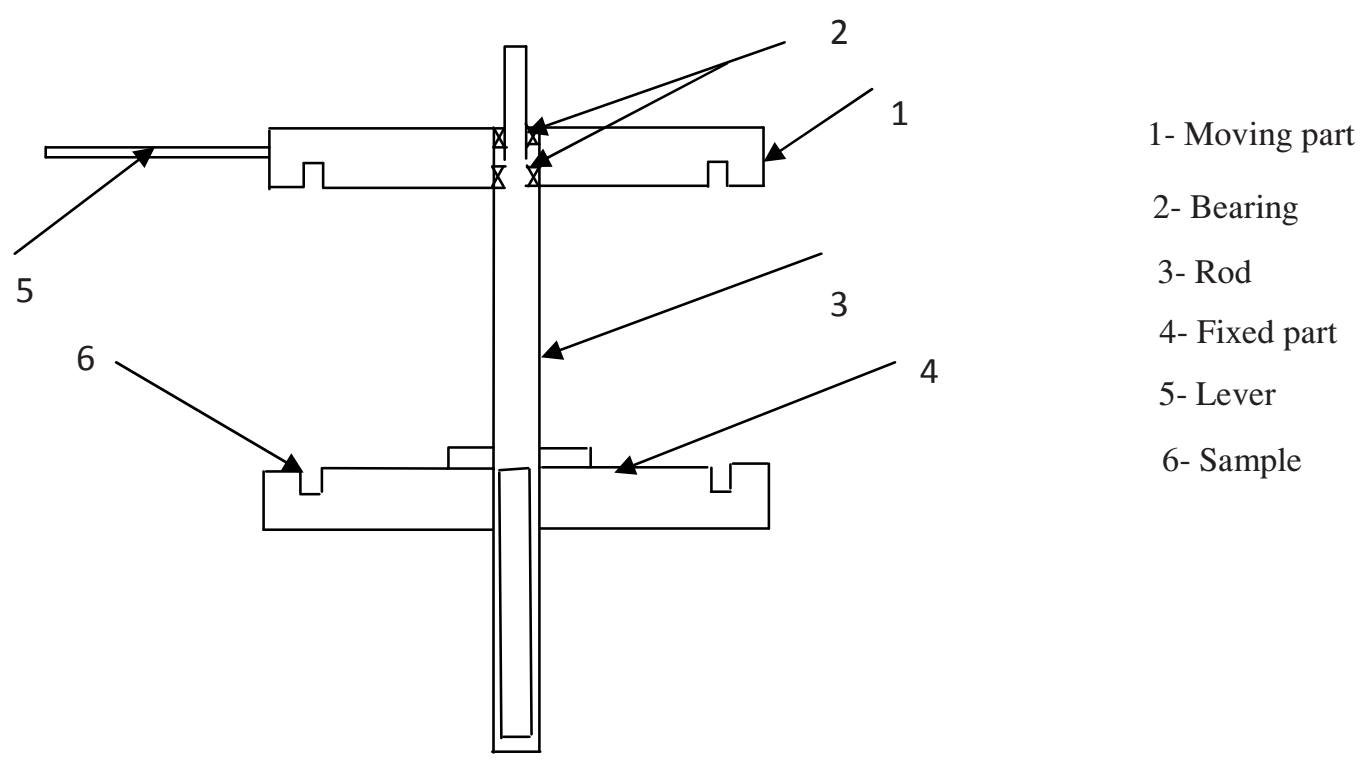

fig.3 experimental device for shearing test.

We stick the two ends of the sample to the aluminium disks which are fixed to each other through a metal rod. One edge of the cylinder is fixed and the other is free, so that applying a load through a lever arm enables us to create torsion (fig.4-5-6). Measuring the (vertical) linear displacements makes it possible to calculate the shearing deformation and hence the instantaneous shearing modulus G. The choice of the applied load depends of the failure load, and then for the $0.35 \tau_{\text {rupture }}$, 
$0.4 \tau_{\text {rupture, }}, 0.5 \tau_{\text {rupture }}$ and $0.6 \tau_{\text {rupture }}$ strain levels we plot the shearing deformation as a function of time (0 to 400 hours).

Torsion strain:

$\tau=\mathrm{M} / \mathrm{W} \quad(1) \quad$ where $\mathrm{M}=$ torsion moment $; \mathrm{W}=$ static stiffness moment

on a $\tau=\mathrm{G} / \gamma$ (2) $\mathrm{G}$ shearing modulus, $\gamma$ shearing deformation

$\gamma=\mathrm{D} . \delta / 2.1 . \mathrm{R}_{\text {ind }}$ (3) 1 length of the sample, $\delta$ vertical linear displacement under the load $\alpha \mathrm{P}_{\text {rupture }}$

D: Outer diameter of the sample, $\mathrm{R}_{\text {ind }}$ : distance between the centre of the cylinder and the point where the load is applied.

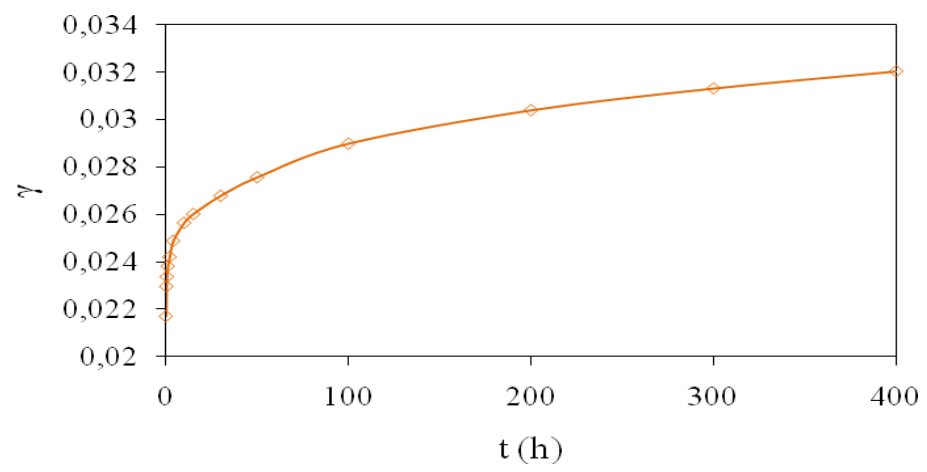

Figure.4. Shearing deformation of polyurethane with time $\left(\tau=0.35 \tau_{\text {failure }}\right)$

The statistical study of the shearing deformations for the different loadings of the samples gives the values indicated on the figures for the following times: $0 ; 0-5 \mathrm{~s} ; 0.25 \mathrm{~h} ; 0.5 \mathrm{~h} ; 1 \mathrm{~h} ; 2 \mathrm{~h} ; 3 \mathrm{~h} ; 4 \mathrm{~h} ; 8 \mathrm{~h}$; 10h; 15h ; 30h ; 50h ; 100h ; 150h ; 200h ; 300h ; 400h. In our case we need the deformations during the first hour in order to determine the instantaneous shearing modulus (table 1).

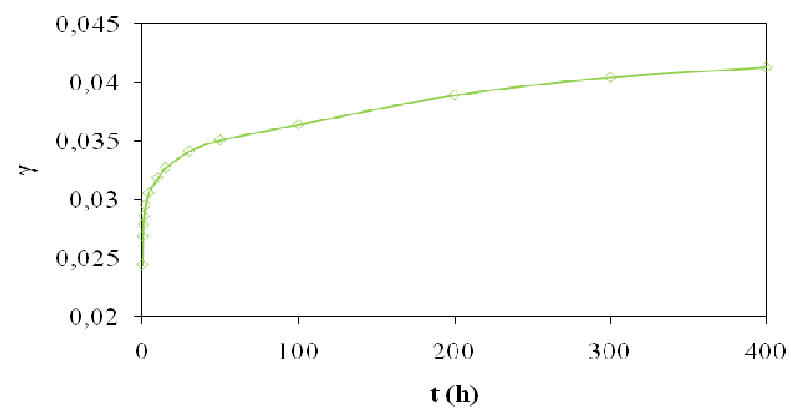

Figure.5. Shearing deformation of polyurethane with time $\left(\tau=0.4 \tau_{\text {failure }}\right)$ 


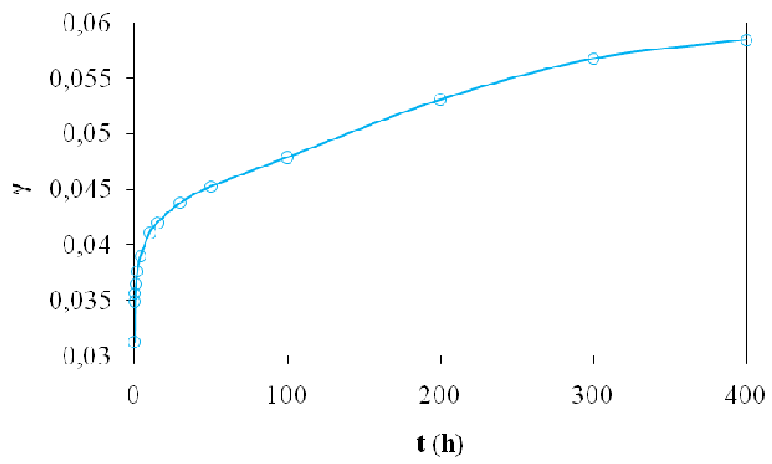

Figure.6 .Shearing deformation of polyurethane with time

\section{V) Experimental value of the shearing modulus}

The shearing deformation values measured during the first hour yield a representative value for the instantaneous shearing modulus using Malmeister relations [6]. Equations (1-3) enable the calculation of this value for the relevant material

\begin{tabular}{|l|l|l|}
\cline { 2 - 3 } \multicolumn{1}{c|}{} & $\begin{array}{l}\text { shearing modulus } \mathrm{G} \\
\left(\mathrm{kg} / \mathrm{cm}^{2}\right)\end{array}$ & $\begin{array}{l}\text { Long term shearing modulus } \\
\mathrm{Kg} / \mathrm{cm}^{2}\end{array}$ \\
\hline polyurethane & 37,058 & 22,8 \\
\hline polystyrene & 32,7 & 19,75 \\
\hline
\end{tabular}

Table. 1 .Shearing modulus of the core materials

\section{VI) Specimen dimensions and test results in three bending test :}

$\mathrm{L}=60 \mathrm{~cm} \mathrm{t}=0.1 \mathrm{~cm}, \mathrm{~h}_{1}=0.5 \mathrm{~cm}$ (polyurethane ), $\mathrm{h}_{2}=1.8 \mathrm{~cm}$ (polystyrene), $\mathrm{b}=10 \mathrm{~cm}$

\begin{tabular}{|l|l|l|l|}
\hline $\begin{array}{l}\text { Three point bending test } \\
\mathrm{P}=40 \mathrm{~kg}\end{array}$ & Results of tests & $\begin{array}{l}\text { Results of theoritical } \\
\text { methods }\end{array}$ & comparison \\
\hline Instantaneous deflection & 0,50 & 0,54 & $8 \%$ \\
\hline Long term deflection & 0,83 & 0,96 & $15,6 \%$ \\
\hline Creep $(\%)$ & 66 & 77 & \\
\hline
\end{tabular}

Table.2. results of three bending test 


\section{Conclusion:}

The physical characteristics of the two materials used for the web in this new design are close in values and similar in behavior. Tests for the determination the instant and long term shear modulus were conducted. Throughout the tests these two materials (polyurethane and polystyrene) displayed a viscoelastic behavior (low density). Tests result of a three point bending showed that the instantaneous and long term deformations (creep) are consistent with the computed values. This new beam design allowed a better use of the bonding characteristics of the polyurethane without using an external agent like glue; it also substantially reduced its thickness without diminishing the mechanical strength of the sandwich beam (initially designed with a homogeneous material such as polyurethane). This substitution resulted in a lower cost of the beam; the polystyrene material is less expensive.

\section{References}

[1] D. Zenkert . An introduction to sandwich construction .Sheffield,UK:Engineering Materials Advisory Service; 1995.

[2] S.D.Clarck, R.A. Shenol \& H.G.Allen. Fatigue characteristics of FRP sandwich Beams for marine applicationsShip Science Report Nº67 May 1993

[3] H.Altenbach ,J.Altenbach,W.Kissing. Mechanics of Composite Structural Elements.Springer.2004.

[4] Jean-Marie Berthelot. Matériaux Composites .Lavoisier.4 édition.2005.

[5] Jacques Renard. Elaboration microstructure et comportement des matériaux composites à matrices polymères. Lavoisier .2005

[6] Malmeister A.K ,Tamouj B.P, Tegera G.A .Resistance of hard polymers.Riga.Zinatia,1967. 